\title{
Hacia un control inmunológico de la toxocariasis: inmunoprotección en canes con antígenos de Toxocara canis
}

\author{
Martín, U.O. ${ }^{1}$; Cordani, F.M. ${ }^{1}$; Demonte, M.A..; Pepino, S. ${ }^{2}$; García, L.D. ${ }^{3}$ \\ ${ }^{1}$ Centro Investig. Endem. Nac., Fac.Bioq.y Cs.Biol., Univ.Nac.Litoral, Ciudad Univ., 3000-Santa Fe, Argentina, \\ Tel.+54 342 4575208. E-mail: umartin@fbcb.unl.edu.ar. ${ }^{2}$ Cát. Peq.Anim. Fac.Cs.Vet.Univ.Nac.Litoral, \\ Esperanza, Santa Fe, Argentina. ${ }^{3}$ Inst. Med. Reg. UNNE, Resistencia, Chaco, Argentina.
}

\begin{abstract}
Resumen
Martín, U.O.; Cordani, F.M.; Demonte, M.A.; Pepino, S.; García, L.D.: Hacia un control inmunológico de la toxocariasis: inmunoprotección en canes con antígenos de Toxocara canis. Rev. vet. 27: 1, 28-31, 2016. Tanto en perros como en seres humanos la toxocariasis se controla con el uso de drogas antiparasitarias. Su continuo uso produce resistencia en el hospedero. El perro es fundamental en la contaminación del ambiente con huevos de Toxocara canis y posterior transmisión accidental de ellos al hombre. Interrumpir la cadena epidemiológica de transmisión es primordial. En este ensayo preliminar se investigó la inmunoprotección en canes con antígenos de T. canis. Se inocularon cinco perros: dos (una hembra y un macho) con antígenos de excreción-secreción, dos hembras con antígenos escondidos y un macho destinado como control. A los 15 días de la segunda dosis, todos los animales fueron infectados con 500 huevos larvados de T. canis. A los 25 días los perros fueron desparasitados, registrándose la carga parasitaria como indicador de efectividad de la inoculación. Todos mostraron huevos en el día 25 post desafío y la posterior negativización a los 20 días en los inmunizados. En el perro control, la cantidad de huevos fue mayor en el día 25 post desafío que en los animales del grupo experimental y aumentó aún más en los días posteriores. Estos resultados iniciales permiten estimular los estudios de selección de antígenos e inmunoprotección con miras a la obtención de un sistema vacunal para canes. La bibliografía internacional no muestra experiencias similares en la unidad T. canis-perro.
\end{abstract}

Palabras clave: perro, toxocariosis, antígenos, inmunoprotección.

\begin{abstract}
Martín, U.O.; Cordani, F.M.; Demonte, M.A.; Pepino, S.; García, L.D.: Towards an immunological control of the toxocariasis: dogs' immunoprotection with Toxocara canis antigens. Rev. vet. 27: 1, 28-31, 2016. In dogs and humans toxocariasis is controlled with the use of antiparasitic drugs. Its continued use generates resistance in the parasite. The dog is crucial in the environmental contamination with Toxocara canis eggs and subsequent accidental human transmission. Interrupting the epidemiological chain of transmission is fundamental. In this preliminary study, immunoprotection is investigated in dogs with $T$. canis antigens. For this purpose, five dogs were inoculated: two (one female and one male) with excretory-secretory antigens and two (females) with hidden antigens. A male was intended as a control. At 15 days after the second dose, all animals were challenged with $500 \mathrm{~T}$. canis larvated eggs. At 25 days dogs were dewormed, and parasite loads were registered as indicator of effectiveness of the inoculation. All the animals showed eggs at day 25 post challenge and the subsequent negative result after 20 days in immunized dogs. In the control dog the number of eggs was higher on day 25 post challenge compared to experimental animals, being even higher in the following days. These initial results encourage studies for the selection of antigens and immune protection as preliminary tests in order to develop a vaccination protocol for dogs. No previous references regarding these types of assays were found in the scientific literature.
\end{abstract}

Key words: dog, toxocariasis, antigens, immunoprotection. 


\section{INTRODUCCIÓN}

Las helmintiasis infectan a más de 700 millones de seres humanos en forma crónica y son consideradas como las más importantes de las enfermedades desatendidas y las segundas infecciones parasitarias después de la malaria ${ }^{10}$. Estas parasitosis a menudo causan sintomatologías muy severas en los niños, en especial en poblaciones vulnerables ${ }^{19}$.

Los datos mundiales de seroprevalencia de Toxocara canis en seres humanos muestran valores que van de 1,6 hasta 92,8\%. En Argentina se reportaron porcentajes de $37,9 \%$ en una población infantil de la ciudad de Resistencia ${ }^{2}$; $39 \%$ en población infantil de clínicas y hospitales de la ciudad de La Plata ${ }^{21} ; 22,1 \%$ en dadores de sangre de la ciudad de Gualeguaychu ${ }^{16} ; 38,9 \%$ en una población adulta sana de la ciudad de Resistencia ${ }^{3}$; $23 \%$ en población rural de General Mansilla, Provincia de Buenos Aires ${ }^{7}$; y $61,5 \%$ en niños carenciados de edad escolar en Corrientes ${ }^{5}$.

El diagnóstico, al igual que los estudios seroepidemiológicos, se realizan mediante la detección de anticuerpos anti-T. canis en sangre. La técnica de elección, el test de ELISA (Enzyme-Linked Immuno Sorbent Assay), utiliza como antígeno los productos de excreción-secreción de larvas de segundo estadio (TES) ${ }^{8}$ mantenidas en un medio de cultivo libre de proteínas.

La cadena epidemiológica de esta parasitosis demuestra la importancia del perro en la transmisión de la infección al ser humano. El control químico a base de drogas antihelmínticas es la medida más adecuada en el control de T.canis en seres humanos y canes aunque diferentes trabajos demuestran que luego de varias desparasitaciones se produce resistencia al antihelmíntico utilizado ${ }^{22,23}$.

Estos hechos ponen en evidencia la necesidad de desarrollar nuevos y más apropiados procedimientos de control, previniendo la infección ${ }^{11}$. Un ejemplo de ello podría ser la implementación futura de un sistema de vacunación en perros. Como estudio previo a la inmunoprotección, es fundamental identificar los antígenos a ser utilizados.

Diferentes autores han publicado experiencias de inmunoprotección con $T$. canis en animales de experimentación ${ }^{1,4,18}$, pero ninguno fue realizado en canes. En los últimos años se han obtenido progresos en el clonado y la expresión de antígenos protectivos de una gran cantidad de parásitos, varias de estas experiencias han fallado al no estimular niveles adecuados de inmunidad en las pruebas realizadas. La evaluación de la eficacia de inmunoprotección fue realizada a través de la investigación de parásitos en materia fecal de animales inmunizados y controles ${ }^{12,13}$.

El hospedero que recibe la dosis infectiva y su sistema inmune, son variables importantes en la eficacia del procedimiento, como también la dosis, la vía de inoculación y la utilización de ciertos adyuvantes que potencian la respuesta inmune ${ }^{20}$. Los TES son antígenos asociados a la superficie larval y secretados por larvas de estadios Larva 2 de T.canis y los antígenos escondidos u ocultos pertenecen a la estructura intestinal interna del parásito y son complejos de antígenos que no son expuestos al sistema inmune del hospedero en su ciclo de vida.

Los antígenos TES han sido postulados como candidatos vacunales ${ }^{15}$, aunque los antígenos ocultos 0 escondidos podrían ser una mejor alternativa ${ }^{17}$, incluso existen investigadores que proponen la utilización de dos antígenos o complejos antigénicos como una alternativa positiva ${ }^{6}$. No existen trabajos publicados realizados en la unidad de análisis $T$. canis-perro ${ }^{10}$. Tampoco una hipótesis inmunológica que sustente la actuación de los antígenos escondidos en inmunoprotección ${ }^{16} \mathrm{o}$ investigue antígenos naturales ${ }^{14}$.

El objetivo de este trabajo fue realizar un ensayo inicial de inmunoprotección a $T$. canis en perros, utilizando antígenos de excreción-secreción y antígenos escondidos.

\section{MATERIAL Y MÉTODOS}

Animales hospederos definitivos. Para realizar las pruebas de inmunoprotección se seleccionaron cinco canes mestizos de 60 días ${ }^{13}$, tres hembras y dos machos, previamente desparasitados. Los perros se mantuvieron en caniles y recibieron asistencia veterinaria clínica y cardiológica continua.

Parásitos y antígenos. Se utilizaron forma adultas de T.canis recolectadas de deposiciones de canes de la zona o extraídas por tratamiento antiparasitario. Los huevos obtenidos de las hembras adultas se mantuvieron 30 días en solución fisiológica formolada para que larven ${ }^{8}$. Luego fueron lavados con solución fisiológica estéril (SFE) y se mantuvieron en medio RPMI-1640 (ICN Biomedicals Inc., Ohio, EEUU). En este periodo los complejos antigénicos fueron extraídos del sobrenadante de cultivo de larvas. Se ensayaron dos inmunógenos: los que contenían antígenos de excreciónsecreción ${ }^{18}$ y los que incluían antígenos escondidos u ocultos ${ }^{17}$. De las hembras adultas extraídas del medio RPMI-1640 donde se mantenían, fueron seleccionadas aquéllas con más de 9 centímetros de longitud y fueron utilizadas para la preparación de TES de acuerdo a una técnica clásica ${ }^{8}$. Entre los adultos machos, fueron considerados aquéllos menores de 6 centímetros de largo, utilizando su intestino para producir AE.

Inmunógenos. Fueron preparados como complejos antigénicos TES, para las inoculaciones en dos canes (hembra y macho) y complejos AE de T.canis, a ser inoculados en dos hembras. Ambos poseían adyuvante completo de Freund (ACF) e hidróxido de aluminio (HA) como adyuvantes.

Inmunización. Se inocularon dos perros con antígenos TES, una hembra de $2,1 \mathrm{~kg}$ (perro $\mathrm{N}^{\circ} 1$ ) y un macho de 2,1 kg (perro $\mathrm{N}^{\circ} 2$ ). Otras dos hembras (de 1,9 y $2,18 \mathrm{~kg}$ ) se inocularon con $\mathrm{AE}$ (perros $\mathrm{N}^{\circ} 3$ y $\mathrm{N}^{\circ}$ 4 respectivamente). Un perro macho de $1,9 \mathrm{~kg}$ operó como control (perro $\mathrm{N}^{\circ}$ 5). La inoculación se realizó en 
los cuartos delanteros utilizando la vía intramuscular. En los canes 1 y 2 la primera dosis del inmunógeno se compuso de $0,5 \mathrm{ml}$ de ACF, $0,5 \mathrm{ml}$ de HA y $1 \mathrm{ml}$ de antígeno TES de concentración $36 \mu \mathrm{g} / \mathrm{ml}$ (vol. total $=2$ $\mathrm{ml}$ ). La segunda dosis se compuso de $0,5 \mathrm{ml}$ de adyuvante incompleto de Freund (AIF), $0,5 \mathrm{ml}$ de HA y $1 \mathrm{ml}$ de antígeno TES de concentración $36 \mu \mathrm{g} / \mathrm{ml}$ (vol. total $=2 \mathrm{ml}$ ). Los canes 3 y 4 , fueron inmunizados con AE. La primera dosis de inmunógeno se compuso de $0,5 \mathrm{ml}$ de ACF, $0,5 \mathrm{ml}$ de $\mathrm{HA}$ y $1,0 \mathrm{ml}$ de $\mathrm{AE}$ de concentración $366,3 \mu \mathrm{g} / \mathrm{ml}$. La segunda dosis contenía $0,5 \mathrm{ml}$ de AIF, $0,5 \mathrm{ml}$ de HA y $1,0 \mathrm{ml}$ de AE, de concentración 366,3 $\mu \mathrm{g} / \mathrm{ml}$. (vol. total $=2 \mathrm{ml}$ ). El animal 5 se inmunizó con una primera dosis de $0,5 \mathrm{ml}$ de $\mathrm{AFC}, 0,5 \mathrm{ml}$ de $\mathrm{HA}$ y 1 $\mathrm{ml}$ de SFE. La segunda dosis se compuso de $0,5 \mathrm{ml}$ de AFI, $0,5 \mathrm{ml}$ de HA y $1 \mathrm{ml}$ de SFE.

Infección. A los 15 días de la última inoculación, a través de una cánula introducida por el hocico, se depositaron en el estómago 500 huevos larvados de T.canis suspendidos en SFE.

Recuentos de huevos de T.canis en materia fecal. Se realizaron a los 25 días de la segunda inmunización y una vez cumplido el ciclo parasitario. Se emplearon dos procedimientos: a) la técnica de McMaster para examen microscópico de suspensión fecal en solución sobresaturada de cloruro de sodio (recuento de huevos y cálculo de huevos por gramo de heces (hpg); b) el método de Wisconsin modificado, basado en la centrifugación-flotación-sedimentación de muestras de materia fecal de canes en una solución sobresaturada de azúcar. La cronología de los procedimientos realizados se resumen en Tabla 1.

\section{RESULTADOS Y DISCUSIÓN}

En la Tabla 2 se consigna el número de huevos por gramo de material fecal obtenido por microscopía óptica, utilizando para todas las muestras la misma cantidad de heces en un mismo volumen de las soluciones empleadas.

No se observó presencia de parásitos adultos en los animales estudiados. Los cachorros acusaban dolor en el lugar de la primera inoculación, sin presentar decaimiento. No se observaron síntomas asociados al rechazo de vacuna ni efectos adversos. En el perro control la cantidad de huevos hallada fue importante en el día 115 y siguió aumentando significativamente hasta el día 123.

Todos los animales inmunizados mostraron huevos de T.canis en el día 115 pero no en el día 123. La perra número 4, inmunizada con $\mathrm{AE}$, eliminó huevos en los primeros días y en el día 115, para luego disminuir hasta alcanzar escasa cantidad, sin llegar a negativizarse como los demás. La negativización de huevos hallada en el día 123 en los perros 1 y 2 inmunizados con TES, y en el animal 3 inmunizado con AE, además de la disminución marcada de huevos en la hembra 4 , indicarían resultados de eficacia que contribuyen a considerar una perspectiva futura alentadora para los fines perseguidos en este trabajo.
Tabla 1. Cronograma del protocolo de inmunización.

\begin{tabular}{|c|c|}
\hline edad & actividad \\
\hline 60 días & $\begin{array}{l}1^{\text {a }} \text { dosis: TES } 36 \mu \mathrm{g} / \mathrm{ml} \text { (perros } 1 \text { y } 2 \text { ) ó } \\
\text { AE } 366,3 \mu \mathrm{g} / \mathrm{ml} \text { (perros } 3 \text { y } 4)\end{array}$ \\
\hline 75 días & $\begin{array}{l}2^{\mathrm{a}} \text { dosis: TES } 36 \mu \mathrm{g} / \mathrm{ml} \text { (perros } 1 \text { y } 2 \text { ) ó } \\
\text { AE } 366,3 \mu \mathrm{g} / \mathrm{ml} \text { (perros } 3 \text { y } 4 \text { ) }\end{array}$ \\
\hline 90 días & búsqueda de parásitos \\
\hline 91 días & $\begin{array}{l}\text { infección-desafío con } 500 \text { huevos larvados de } \\
\text { T. canis }\end{array}$ \\
\hline 115 días & control de huevos en materia fecal \\
\hline 123 días & $\begin{array}{l}\text { desparasitación, conteo de huevos en heces, } \\
\text { extracción de sangre }\end{array}$ \\
\hline
\end{tabular}

TES: antígenos de excreción-secreción. AE: antígeno escondido.

Tabla 2. Recuento de huevos en materia fecal de canes, pre y post desafío.

\begin{tabular}{ccccccc}
\hline perro & $\begin{array}{c}\text { días 0-60 } \\
\text { pre-infección) } \\
\text { Wisconsin } \\
\text { McMaster }\end{array}$ & $\begin{array}{c}\text { día 115 } \\
\text { post-infección } \\
\text { Wisconsin } \\
\text { McMaster }\end{array}$ & $\begin{array}{c}\text { día 123 } \\
\text { post-infección } \\
\text { Wisconsin } \\
\text { McMaster }\end{array}$ \\
\hline 1 & 0 & 0 & 93 & 190 & 0 & 0 \\
2 & 0 & 0 & 55 & 98 & 0 & 0 \\
3 & 0 & 0 & 10 & 30 & 0 & 0 \\
4 & 52 & 100 & 90 & 200 & 8 & 90 \\
5 & 0 & 0 & 54 & 80 & 110 & 240 \\
\hline
\end{tabular}

Perros 1 y 2: inmunizados con TES. Perros 3 y 4: inmunizados con AE. Perro: 5 control.

Parecería ser que ante la inmunización, la respuesta inmune no actúa inmediatamente sino después de unos días, como lo demuestra la observación del día 115 con parásitos y el día 123 sin ellos. Es posible que la vacunación sea más efectiva si se realiza una primera dosis en animales de tres meses de edad, con un sistema inmune más desarrollado, mejorando así la respuesta, como aseveran otros investigadores ${ }^{12}$.

Otra consideración a tener en cuenta es que el cómputo de huevos no es un parámetro exacto, no obstante lo cual permite evidenciar el efecto biológico del ensayo. Con respecto al sexo de los animales utilizados, las hembras mostraron una mayor resistencia en comparación con los machos, quizás por la defensa de la descendencia involucrada en la naturaleza de la procreación propia de este sexo ${ }^{9}$.

El uso de adyuvantes podría ser optimizado a los fines de que las inoculaciones no provoquen molestias en los hospederos. El número de animales utilizados para este estudio fue considerado a partir de comparaciones con avanzados grupos de investigación ${ }^{13}$ No existen comunicaciones sobre experiencias de inmunoprotección en este sistema T. canis-perro ${ }^{10}$.

Estos resultados previos permiten vislumbrar una futura inmunoproteccion capaz de acrecentar los recursos de la salud pública, dada la inexistencia de vacunas efectivas para proteger animales y seres humanos de esta infección helmíntica. 
Agradecimientos. A la Universidad Nacional del Litoral por haber financiado el trabajo. A las Profesoras Nelsa Widerhorn y Elsa Giraldez por su valioso asesoramiento. La investigación fue autorizada por los comités de ética de las instituciones involucradas.

\section{REFERENCIAS}

1. Abo-Shehada MN, Al-Zubaidy BA, Herbert IV. 1991. Acquired immunity to Toxocara canis infection in mice. Vet Parasitol 38: 289-298.

2. Alonso JM, Bojanich MV, Chamorro M, Gorodner J. 2000. Toxocara seroprevalence in children from a subtropical city in Argentina. Rev Inst Med Trop Sao Paulo. 42: 235-237.

3. Alonso JM, Bojanich MV, Marull J. 2004. Infección por Toxocara canis en población adulta de un área subtropical de Argentina. Parasitol Latinoam 59: 61-64.

4. Barriga O. 1988 A critical look at the importance and control of toxocariasis and the possibilities of immunological control. Vet Parasitol 2: 195-234.

5. Bojanich MV, López MA, Fernandez G, Azula L, Alonso JM. 2008. Infección por Toxocara canis en población infantil vulnerable del noreste de Argentina. Enf Emerg 10: 60-64.

6. Brooker S, Bethony JM, Rodriguez L, Alexander N, Geiger S. 2005. Epidemiological, immunological and practical consideration in developing and evaluating a human hookworm vaccine. Expert Rev Vacc 4: 35-50.

7. Chiodo P, Basualdo J, Ciarmela L, Pezzani B, Apesteguía M, Minvielle M. 2006. Related factors to human toxocariasis in a rural community of Argentina. Mem Inst Oswaldo Cruz 101: 397-400.

8. De Savigny DH. 1979. Toxocariasis and serological diagnoses by enzyme immuno sorbent assay. J Clin Pathol 32: 284-288.

9. Fujiwara RT, Geiger SM, Bethony J, Mendez S. 2006. Comparative immunology of human and animal models of hookworm infection. Parasite Immunol 28: 285-293.

10. Hewitson JP, Maizels RM. 2014. Vaccination against helminth parasite infections. Expert Rev Vacc 13: 473-487.

11. Hotez PJ, Demert D, Bacon KM, Bethony JM. 2013. The human hookworm vaccines. Vaccine 315: B227-B232.
12. Loukas A, Bethony JM, Williamson AL, Gaddan NG, Mendez S. 2004. Vaccination of dogs with a recombinant cysteine protease from the intestine of canine hookworms diminishes the fecundity and growth of worms. $J$ Inf Dis 189: 1952-1961.

13. Loukas A, Bethony JM, Mendez S. 2005. Vaccination with recombinant aspartico hemoglobinase reduces parasite load and blood loss alter hookworm infection in dogs. PLoS Med 2: e295.

14. McSorley HJ, Hewitson JP, Maizels RM. 2013. Immunomodulation by helminth parasites: Defining mechanisms and mediators. Int J Parasitol 43: 301-310.

15. Meeusen E. 1996. Rational design of nematode vaccines: Natural Antigens. Int J Parasitol 26: 813-818.

16. Minvielle M, Taus M, Raffo M, Ciarmela L, Basualdo JA. 2000. Seroprevalence of Toxocariasis in blood donors of Gualeguaychu, Argentina. Trans Roy Trop Med Hyg 94: 373-375.

17. Munn E. 1997. Rational design of nematode vaccines: Hidden Antigens. Int J Parasitol 27: 359-366.

18. Nicholas WL, Stewart AC, Mitchell GF. 1984. Antibody responses to Toxocara canis using sera parasite-infected mice, and protection from toxocariasis by immunization with ES antigens. Austr J Exp Biol \& Med Sci 62: 619-626.

19. Panamerican Health Organization. 2011. Un llamado a la acción: hacer frente a los helmintos transmitidos por el contacto con el suelo en Latinoamérica y el Caribe. Neglected Trop. Dis. Public. Sabin Vaccine Institute, BID,OPS/OMS, Texas (USA).

20. Piedrafita D, Preston S, Kemp J, Veer M, Sherrard J. 2013. The effect of different adjuvants on immune parameters and protection following vaccination of sheep with a larval-specific antigen of the gastrointestinal nematode, Haemonchus contortus. PLoS One. 21: 8, e78357.

21. Radman N, Archelli S, Fonrouge R. 2000. Human toxocariasis. Its seroprevalence in the city of La Plata. Mem Inst Oswaldo Cruz 95: 281-285.

22. Sangster N. 1999. Anthelmintic resistance: past, present and future. Int J Parasitol 29: 115-124.

23. Wescott RB. 1986. Anthelmintics and drug resistance. Vet Clin North Am 2: 367-380. 